OCT 28 1965

\title{
NBS
}

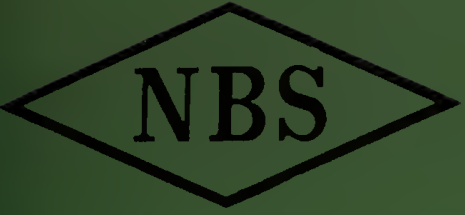

Eechnical Note

no. 77

Boulder Laboratories

\section{VHF AND UHF POWER GENERATORS FOR}

RF INSTRUMENTATION

BY

A. H. MORGAN AND P.A. HUDSON

U. S. DEPARTMENT OF COMMERCE NATIONAL BUREAU OF STANDARDS 


\section{THE NATIONAL BUREAU OF STANDARDS}

\section{Functions and Activities}

The functions of the National Bureau of Standards are set forth in the Art of Congress, Mards 3. 1901, as amended by Congress in Public Law 619, 1950. These include the development and maintenance of the national standards of measurement and the provision of means and inethods for mahing measurements consistent with these standards: the determination of phy sical constants and properties of materials; the development of methods and instruments for testing materials. deviers. and structures: advisory scrices to government agencies on scientific and tcehnical problems: invention and development of devices to serve special needs of the Government: and the development of standard practices, codes, and specifications. The work includes basic and applied reserareh. developinent, engineering, instrumentation, testing, evaluation, calibration servires. and various consultation and information services. Research projects are also performed for other government agencics when the work relates to and supplements the basie program of the Burean or when the Bureau's unique competence is required. The scope of activities is suggested by the listing of divisions and sections on the inside of the back cover.

\section{Publications}

The results of the Bureau's work take the form of cither actual equipment and deviers or pub. lished papers. These papers appear either in the Bureau's own series of publications or in the journals of professional and scientific societies. The Bureau itself publishes three periodicals available from the Govermucnt Printing office: The Journal of Research, published in four separate sections. presents complete scientifie and technical papers: the Technical News Bulletin presents summary and preliminary reports on worh in progress; and Basic Radio Propagation P'redictions provides data for determining the best frequencies to use for radio commonieations throughont the world. There are also five series of nomperiodical publications: Monographs, Applied Vathematir's Sories, IIandbooks. Miscellaneous Publications, and Technical Votes.

Information on the Bureau's pullications can be found in VBS Circular 160, P'ublications of the Vational Bureau of Standards (\$1.25) and its Supplentent (\$1.50), arailable from the Superintendent of Documents, Governunent Printing ()ffice, Washington 25, D.C. 


\section{NATIONAL BUREAU OF STANDARDS Eechnical Mote}

September 1960

VHF AND UHF POWER GENERATORS FOR RF INSTRUMENTATION

by

A. H. Morgan and P. A. Hudson

NBS Technical Notes are designed to supplement the Bureau's regular publications program. They provide a means for making available scientific data that are of transient or limited interest. Technical Notes may be listed or referred to in the open literature. They are for sale by the Office of Technical Services, U. S. Department of Commerce, Washington 25, D. C.

DISTRIBUTED BY

UNITED STATES DEPARTMENT OF COMMERCE OFFICE OF TECHNICAL SERVICES

WASHINGTON 25, D. C.

Price \$ .75 


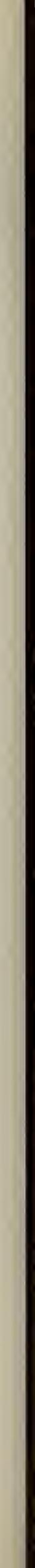


TABLE OF CONTENTS

VHF AND UHF POWER GENERATORS

FOR RF INS TRUMENT A TION

by

A. H. Morgan and P. A. Hudson

Page

ABSTRACT

iii

1. INTRODUCTION 1

1.1 Purpose 1

1. 2 Design Specifications 1

2. EXCITER DESIGN 2

2. 1 Generai Description 3

2. 2 Oscillator Section 3

2. 3 Buffer Stage 3

2.4 Intermediate Amplifiers 4

2. 5 Exciter Output Stage 4

3. 100 WATT POWER AMPLIFIER DESIGN 5

3. I $100 \mathrm{Mc}$ and $200 \mathrm{Mc}$ Circuits 5

3. $2300 \mathrm{Mc}$ and $400 \mathrm{Mc}$ Circuits 5

4. AUTOMATIC LEVEL CONTROL CIRCUIT 6

5. PER FOR MANCE CHAR ACTERISTICS 7

5. 1 Frequency Stability 7

5.2 Output Level Stability 8

5. 3 Spurious Outputs 8

5. 4 Residual Modulation 8

5.5 Shielding 8

6. ACKNOWLEDGMENT 9 


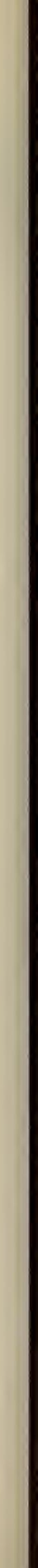


Table of Contents (Continued)

7. FIGURES

1. Generator Circuit Diagram $(400 \mathrm{Mc})$

2. Bottom View of Chassis

3. $100 \mathrm{Mc}$ and $200 \mathrm{Mc}$ Power Amplifier Circuit

4. Plate Cavity for $4 \times 250 \mathrm{~B}$ Tube $300 \mathrm{Mc}$ and $400 \mathrm{Mc}$

5. Automatic Level Control (ALC) Circuit

6. Block Diagram, Typical Connection Procedure When Using Automatic Level Control

7. Generator Tube Layout

8. Front View of Generator With Shield in Place 



\section{ABSTRACT}

The work described in this report was undertaken to provide certain projects in the Radio Standards Division with a series of fixed frequency rf generators having good stability with respect to both frequency and powe $r$ output level and continuously adjustable in power output from 1 to 100 watts. Prior to the completion of the generators the work of some of the standards projects was seriously hampered because the rf generators available were lacking in either sufficient power output, frequency stability, or power output stability. For example, bolometer bridges used for rf voltage and power measurements are sensitive to power input variations as small as a few parts in $10^{4}$. Power stability of at least one part in $10^{3}$ is considered an absolute necessity to obtain measurement accuracies of from $0.5 \%$ to $1 \%$. 

VHF AND UHF POWER GENERATORS

FOR RF INSTRUMENTATION

A. H. Morgan and P. A. Hudson

1. INTRODUCTION

\subsection{Purpose}

The work described in this report was undertaken to provide certain projects in the Radio Standards Division with a series of fixed frequency $\mathrm{rf}$ generators having good stability with respect to both frequency and power output level and continuously adjusted in power output from 1 to 100 watts. Prior to the completion of the generators the work of some of the standards projects was seriously hampered because the rf generators available were lacking in either sufficient power output, frequency stability, or power output stability. For example, bolometer bridges used for rf voltage and power measurements are sensitive to power input level variations as small as a few parts in $10^{4}$. Power stability of at least one part in $10^{3}$ is considered an absolute necessity to obtain measurement accuracies of from $0.5 \%$ to $1 \%$. Good power stability is likewise desirable in the use of $\mathrm{rf}$ calorimetric wattmeters andin the substitution method of attenuation measurement.

Frequency stability is required in many measurements because tuned elements, such as quarter-wave stubs and narrow band detectors, may be part of the measuring system.

A survey of commercially available generators was made but nothing was found at that time (1955) which would satisfy all the requirements. Hence it was decided to design and construct a set of generators in the laboratory.

\section{2 Design Specifications}

A set of design specifications was arrived at after consultation with the project leaders in need of better rf generators. The adopted specifications were as follows:

Frequencies:

Frequency Stability:
$100,200,300,400, \mathrm{Mc}$

Within $0.0005 \%$ after 15 minute warmup 

Power Output:

Power Output Stability:

Residual AM:

Harmonic Content:

Shielding:

Output Impedance:

Duty:

Size:
Continuously adjustable from 1 watt to 100 watts into $50 \mathrm{ohm}$ load

$\pm 0.1 \%$ per hour

Less than $0.05 \%$ of output voltage

$60 \mathrm{db}$ below fundamental with single filter

At least $80 \mathrm{db}$ when generator is enclosed in a shielded rack.

$50 \pm 5 \mathrm{ohms}$

Continuous operation at full power output

Suitable for standard rack mounting

Power output stability and frequency stability were considered of major importance and design features were chosen which enhanced these qualities.

\section{EXCITER DESIGN}

\section{1 General Description}

The arrangement of the exciter part of each generator, with the exception of the $100 \mathrm{Mc}$ unit, consisted of an oscillator-doubler, a buffer stage, an intermediate amplifier and a combined tripler amplifier for the output. In the $100 \mathrm{Mc}$ unit the output was from a straight power amplifier. High frequency crystal units were employed to minimize the number of multiplication stages and to reduce the number of sidebands in the generator output. For example, in the $400 \mathrm{Mc}$ generator the crystal frequency was $66.666 \mathrm{Mc}$. Such crystals were readily available from commercial sources with the desired tolerance.

The choice of tubes in the output stage was determined by available power from the exciter. Each stage of the exciter will be described in the following paragraphs. A circuit diagram for a typical exciter $(400 \mathrm{Mc})$ is shown in Fig. 1 . 



\section{2 Oscillator Section}

The oscillator is a modified Butler type and was chosen because of its simplicity, good frequency stability, and reliability. In addition, the circuit is not critical with respect to design, adjustment, or interchange of tubes (1).

A circuit diagram of the two-stage oscillator section is shown in Fig. 1 a. No claim is made to originality of the design used because numerous modifications of the basic Butler circuit have been made by others including, in all probability, the one described here.

The first stage of the oscillator includes a plate tank circuit tuned to the crystal frequency $f_{C}$ while the plate tank of the second stage is tuned to $2 \mathrm{f}_{C}$. Thus, frequency doubling is accomplished. The plate tank in the first stage, which is a modification of the basic Butler circuit, serves to increase the output of the oscillator. The $100 \mathrm{Mc}$ generators employ $50 \mathrm{Mc}$ crystals and, with the doubling, no further frequency multiplication was necessary. In the 200; 300 and $400 \mathrm{Mc}$ generators the crystal frequency is $1 / 6$ of the exciter output frequenc $y$ with doubling and tripling required. This arrangement was used because the exciter output tube, type 5894, has a high input capacity and it is difficult to effectively employ input frequencies above $160 \mathrm{Mc}$.

\section{3 Buffer Stage}

The purpose of the buffer stage as shown in Fig. $1 \mathrm{~b}$ is, of course, to isolate the oscillator from the amplifier stages and prevent frequency variations due to varying amplifier loading conditions. The design and construction of the stage is straightforward, as shown in Fig. 1 b. The oscillator output is coupled to the $6 \mathrm{AH} 6$ input by a $10 \mu \mu f$ capacitor. With inductive coupling on the input to the $6 \mathrm{AH} 6$ higher output may be obtained, but under those conditions there was a strong tendency to os cillate. The plate tank circuit of the buffer is tuned to the oscillator output frequency with inductive coupling to the following amplifier stage.

(1) "Handbook of Piezolectric Crystals for Radio Equipment Designers", John P. Buchanan, Philco Corporation, Wright Air Development Center. Technical Report 56-156, October 1956. For sale by Office of Technical Services, U. S. Department of Commerce, Washington 25, D. C. 

2. 4 Intermediate Amplifiers

The driving power required for the 5894 exciter output stage is approximately 3 watts when used as a straight push-pull amplifier at $100 \mathrm{Mc}$. When used as a tripler-amplifier, to frequencies of 200,300 and $400 \mathrm{Mc}$, the driving power must be at least 6 watts. Thus, considerable power amplification (approximately $18 \mathrm{db}$ ) must be provided between the buffer and input to the type 5894 tubes. This gain is obtained with two $s$ tages utilizing the type 6360 twin-tetrode tube operating push-pull, class C. As shown in the schematic of Figure $1 \mathrm{c}$, butterfly capacitors are used on both input and output to balance the tank circuits to ground.

In order to prevent oscillation in the intermediate amplifiers a grounded metal shield is placed across the bottom of each tube socket so that the grid tank is shielded from the plate tank. Such an arrangement is shown in Figure 2. The 6360 tubes have tube shields of the heat dissipating type and adequate ventilation also is provided.

\section{5 Exciter Output Stage}

The exciter output stage is operated class C, with grid leak bias, as shown in Fig. $1 \mathrm{~d}$. The value of the grid leak resistor is fairly critical as it determines the proper conduction angle. This is particularly true for the $300 \mathrm{Mc}$ and $400 \mathrm{Mc}$ generators. Operating voltages are given in the standard tube manuals available from the tube manufacturer. The power output is 16 watts for the $400 \mathrm{Mc}$ exciter. At lower frequencies the output powers are as follows: $300 \mathrm{Mc}-22$ watts, $200 \mathrm{Mc}-30$ watts, $100 \mathrm{Mc}-40$ watts. The exciter output is brought out to a type $\mathrm{N}$ jack on the front panel and is connected to the 100 watt power amplifier input jack by a short length of cable. It may be used independently of the power amplifier when desired.

The power output is controlled either manually or by the automatic level control circuit (this is described in Paragraph 4.0). Selection of the method of control is made by means of the triple-pole, double-throw switch which connects the automatic level control circuit to the screen grid of either the 5894 exciter output or the 4 X250 B power amplifier. With the switch in the "PA" position the exciter output is controlled by the rheostat $\left(R_{20}\right.$ in Fig. 1$)$ 

It should be noted that lumped-constant tank circuits are used at all frequencies and that all rf coils are wound with \#10 A. W. G. wire for good efficiency and stability.

\section{I00 WATT POWER AMPLIFIER DESIGN}

\section{3. $1100 \mathrm{Mc}$ and $200 \mathrm{Mc}$ Circuits}

As was mentioned earlier, the $4 \mathrm{X} 250 \mathrm{~B}$ tube is used as the power amplifier in all of the generators described here. This tube is a small radial-beam tetrode rated at 250 watts plate dissipation at frequencies up to $400 \mathrm{Mc}$. With 900 volts on the plate a power output of 120 watts into a $50 \mathrm{ohm}$ load is easily obtainable with class C operation. Link coupling is used on the input to the tube with grid-leak bias of 90 volts as shown in Fig. 3. At 100 and 200 Mc approximately 8 watts of driving power are required.

The plate tank circuits at the se frequencies are lumped-constant type with coils made of relatively large diameter wire. The circuits are series resonant to provide a relatively low impedance for the tube plate in accordance with the tube manufacturers ${ }^{p}$ recommendation. In general, better coupling can be achieved on both the input and output if the coils are mounted coaxially rather than side-by-side. A perforated shield enclosure surrounding the tube, plate tank, and output link improved the performance as well as reduced unwanted radiation.

The tube manufacturers' recommendations for forced-air cooling of the tube were followed.

\section{2 $300 \mathrm{Mc}$ and $400 \mathrm{Mc}$ Circuits}

At frequencies of $300 \mathrm{Mc}$ and above, the use of lumped-constant tank circuits and output loops with the $4 \times 250 \mathrm{~B}$ appeared to be marginal. That is, with 900 volts on the plate of the tube, an output of 100 watts could only be obtained with the tube operating at maximum allowable plate dissipation. Since this type of operation shortens tube life considerably it was decided to use a quarter-wave cavity for the plate tank. Sectional views of the $400 \mathrm{Mc}$ cavity are shown in Fig. 4. The length of the cavity was made $0.6 \times \frac{\lambda}{4}$, at the operating frequency, in order to better match the output impedance of the tube and to allow for capacitive tuning. With two capacitors the $400 \mathrm{Mc}$ cavity tunes from $340 \mathrm{Mc}$ to $430 \mathrm{Mc}$ while the $300 \mathrm{Mc}$ cavity tunes from $270 \mathrm{Mc}$ to 
$330 \mathrm{Mc}$. Construction of the cavity is relatively simple and can be done in any good machine shop. Contact to the plate of the $4 \times 250 \mathrm{~B}$ is made by a ring of beryllium-copper fingers soldered to the inner cylinder of the cavity.

Using plate cavities for the $4 \times 250 \mathrm{~B}$, load power outputs of 120 watts were obtained with the tube operating at $70 \%$ of maximum plate dissipation. In addition the cavity helps suppress the sub-harmonics normally present in the output of the tripler-exciter.

\section{AUTOMATIC LEVEL CONTROL CIRCUIT}

Measurements and tests on the first prototype if generator $(100 \mathrm{Mc})$ indicated that the specification on output level stability could not be met without extra circuitry for automatic control. This result was at least partly anticipated in view of some prior tests made on commercial rf power generators. It would thus appear that, in generai, equipment of this type does not have the inherent output level stability necessary for instrumentation use.

The automatic level control circuit for the generator described here was designed to control the dc voltage to the screen of the output stage. The control grid of the tube could not be used for this purpose due to the fact that the stage is operated class $C$ and thus the grids are driven to saturation. It was also desired that the circuit not include semiconductor diode rectifiers and reference batteries because of the inherent temperature and peculiar instability of these devices. In the final circuit, shown in Figure 5, a temperature-limited diode is used as the sensing and reference device. Since the diode is temperature limited its plate current is directly proportional to the filament emission current. This emission obeys Richardson's equation and is a very rapidly varying function of filament temperature. That is, doubling the temperature may increase the emission by a factor of $10^{7}(2)$. The filament temperature is, of course, proportional to power input. Even though the filament impedance is small while the plate load impedance can be quite large (of the order of $10^{6} \mathrm{ohm}$ ) it is possible to achieve a voltage gain. In this circuit the gain is approximately 2000. The diode filament is heated directly by a portion of the rf energy from the generator.

Variations in output power cause variations in the plate voltage of the diode which are $180^{\circ}$ out of phase with those of the rf output. This phase difference is maintained through the output of the cathode follower $V_{3}$. The stage $V_{2}$ is a cathode coupled dc amplifier with a

(2) Karl R. Spangenberg, "Vacuum Tubes", McGraw-Hill Book Co., 1948. 

gain of 10. The VR tube $V_{4}$ provides a constant voltage drop between $\mathrm{V}_{3}$ and the screen of the generator output stage. More than one VR tube may be used, when necessary, to provide the proper screen voltage for the generator output tube. In these generators the complete circuit is mounted on the same chassis as the other components and tubes of the generator. A type $\mathrm{N}$ jack is provided on the front panel to feed power to the diode filament. The capacitor $\mathrm{C}_{2}$ may be either fixed or variable and serves to tune out the inductance of the diode filament. When the diode filament emits sufficient current to cause the proper plate current to flow then the control circuit will oppose any further variations in the filament temperature of the diode. Thus there was no need for an external reference voltage in the circuit.

Adjustment of the generator, with the automatic level control, is as follows: Connect the generator to a load through a tee. On one leg of the tee, connect a variable capacitor in series with the center conductor. The capacitor may be mounted inside a small metal box with coaxial connectors on both ends. Small piston type capacitors have been found quite satisfactory. The output end of the capacitor box is then connected back to the input to the temperature-limited diode filament.

The presence of the feed-back capacitor in parallel with the load introduces some mismatch and it is necessary to tune the generator plate-tank and output circuits for minimum dc plate current. A block diagram of a typical setup is shown in Figure 6.

It should be noted that when using a capacitor for feed-back to the diode the load sees a nearly constant-voltage-generator at the tee where the capacitor is connected. Output impedance of the power generator is approximately $0.1 \mathrm{ohm}$. With inductive coupling the generator becomes a nearly constant-current-source and, with a directional coupler, a source of nearly constant incident-power. Adjustme nt of the output level with the latter two devices is, however, not as convenient as with the variable capacitor.

\section{0 PER FORMANCE CHARACTERISTICS}

\section{1 Frequency Stability}

The output frequency stability of the generator is essentially that of the oscillator. The crystals used have a turnover point of $75^{\circ} \mathrm{C}$ and are operated in relatively simple $75^{\circ} \mathrm{C}$ ovens. After warmup the stability is better than 5 parts in $10^{6}$ per hour and 10 parts in $10^{6}$ per day. 



\section{2 Output Level Stability}

Using the automatic level control with a typical generator, the output voltage variations did not exceed $0.5 \%$ per hour. For periods of 10 minutes a maximum variation of the order of 0.05 to $0.1 \%$ may be expected. These figures are from 10 to 20 times better than were found for the same generators without the automatic level control.

\subsection{Spurious Outputs}

The harmonic content of the output voltage varied with the frequency of the generator and with generators at the same frequency. in all cases the harmonic voltages were at least $30 \mathrm{db}$ down from the fundamentals. Where necessary, commercially available filters have been used to reduce spurious outputs to at least 60 db below the fundamental.

\section{4 Residual Modulation}

Residual amplitude modulation in all the generators was found to be mostly at the 60-cycle and 120-cycle frequencies. At these frequencies the residual amplitude modulation was not greater than $0.1 \%$.

Some trouble was experienced with low frequency moduiation due to the vibration of the cooling fans when they were mounted directly on the chassis. This was overcome by mounting the fans remotely and connecting to the chas is with flexible tubing.

\subsection{Shielding}

As was mentioned earlier each tube and tank circuit extending above the chassis was shielded individually by a tube shield or a perforated copper enclosure. In addition the entire generator was enclosed in a copper box with screened openings for forced air cooling. All wires entering the box were through low pass electrical filters. Finally, the gererators were mounted inside special racks which had close-fitting doors and filters for the input power. In Figures 7 and 8 photographs are shown of the shielding, filter box and tube layout. 



\subsection{ACKNOWLEDGMENTS}

The authors are indebted to Mr. C. M. All red for several suggestion $s$ including the use of the temperature-limited diode in the automatic level control circuit and to the following members of the staff for contributing to the development of the generators:

Mr. J. H. Shoaf, Mr. D. H. Russell, and Mr. L. E. Mann 

7. FIGURES 


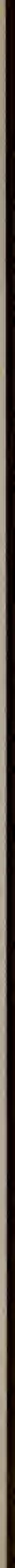




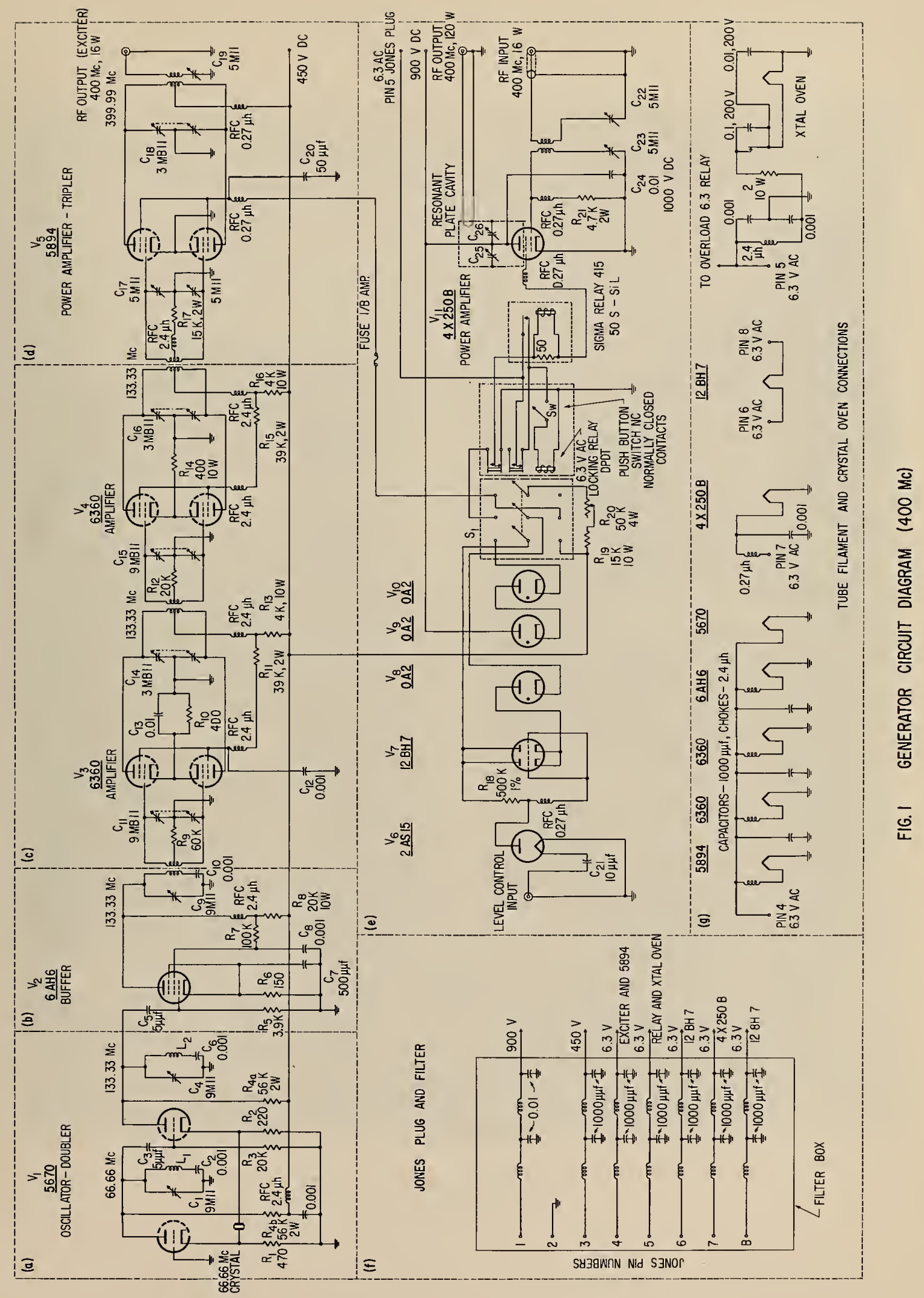




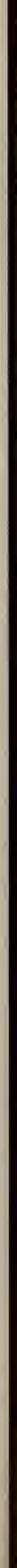




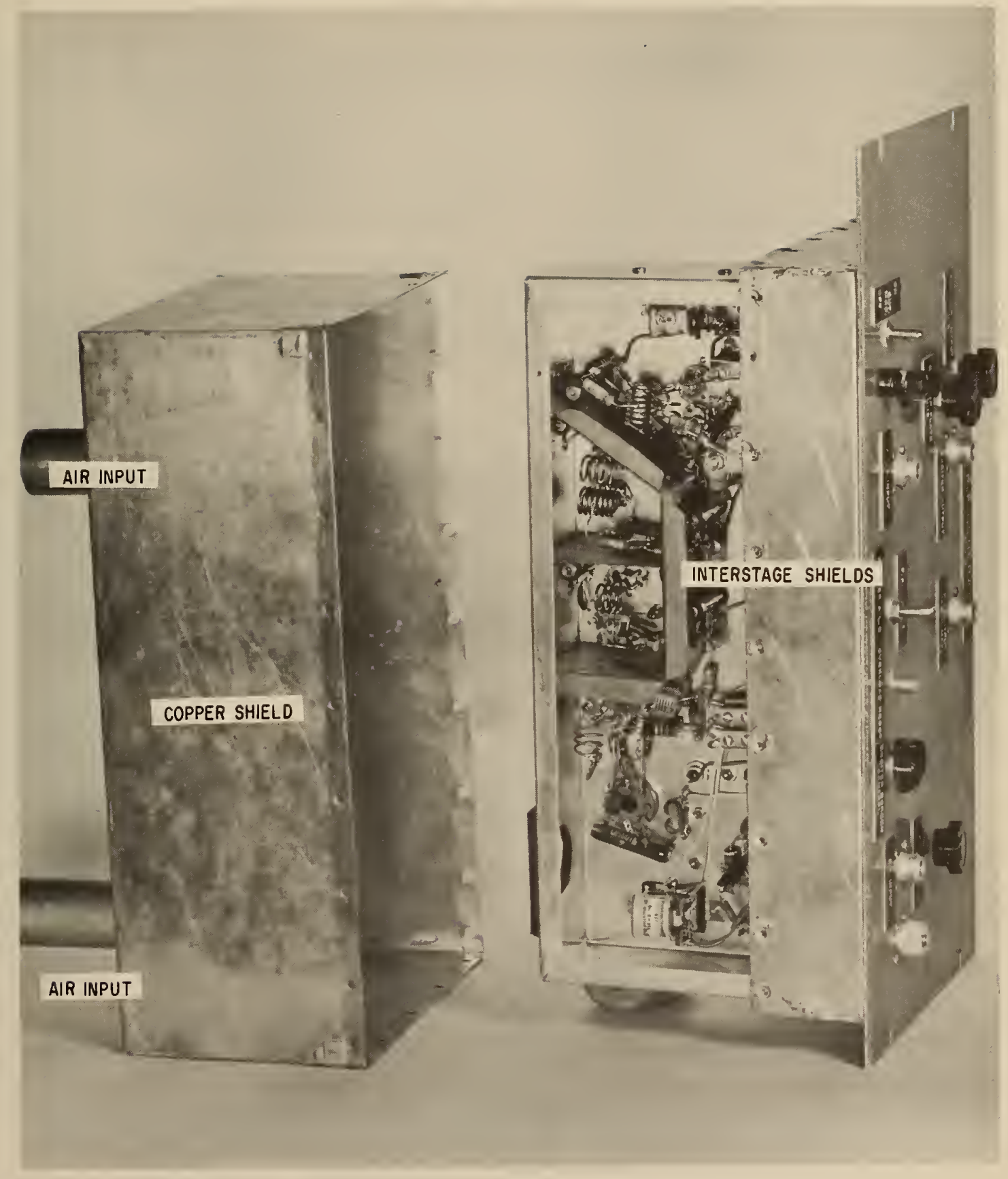

BOT TOM VIEW OF CHASSIS

Figure 2 


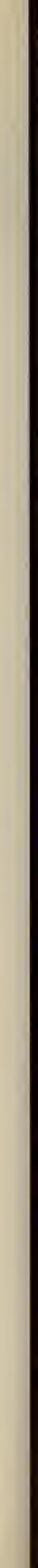




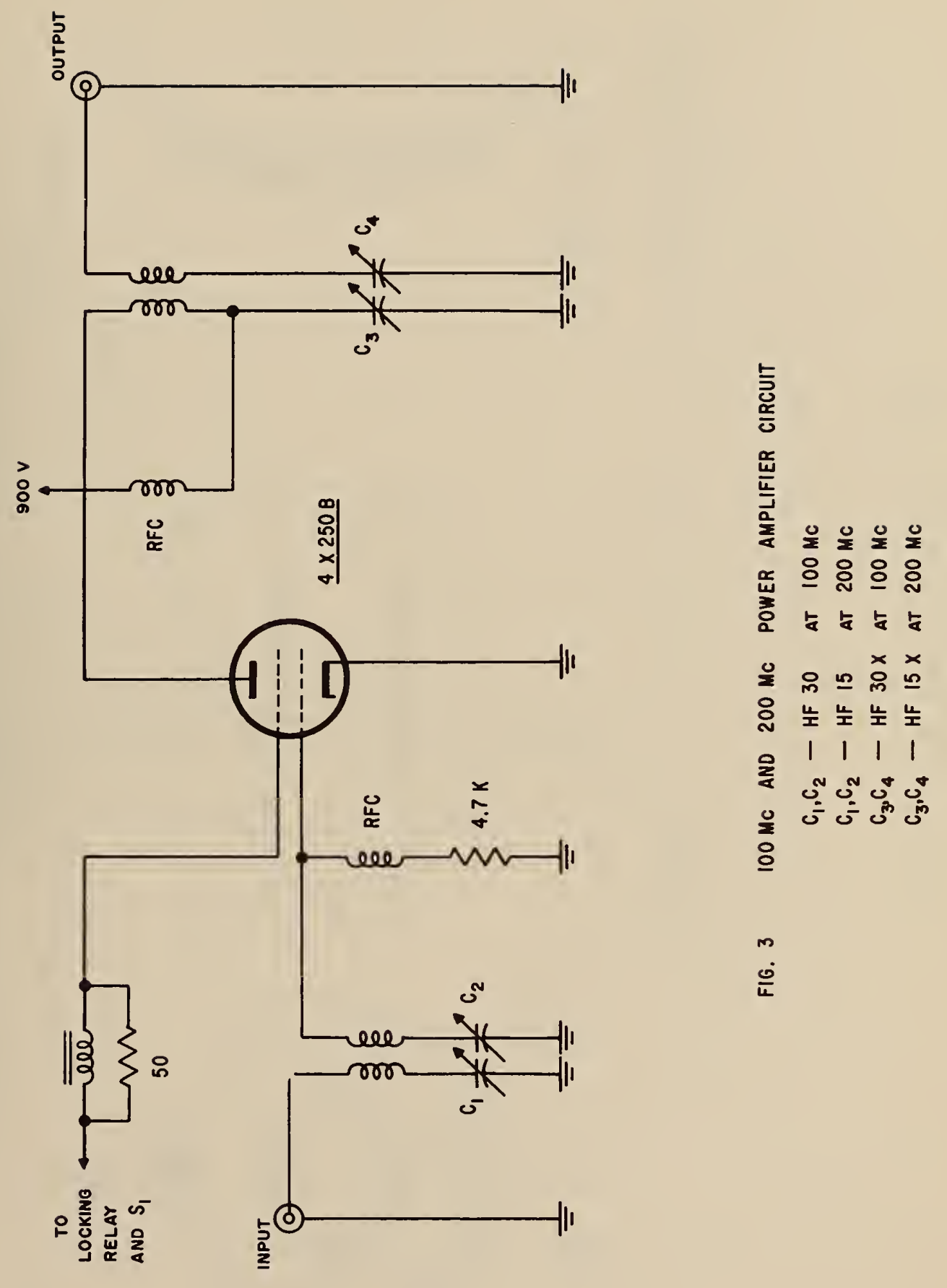




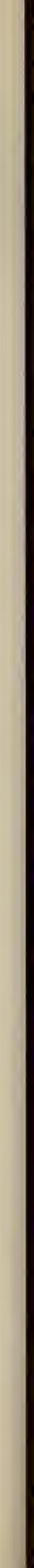




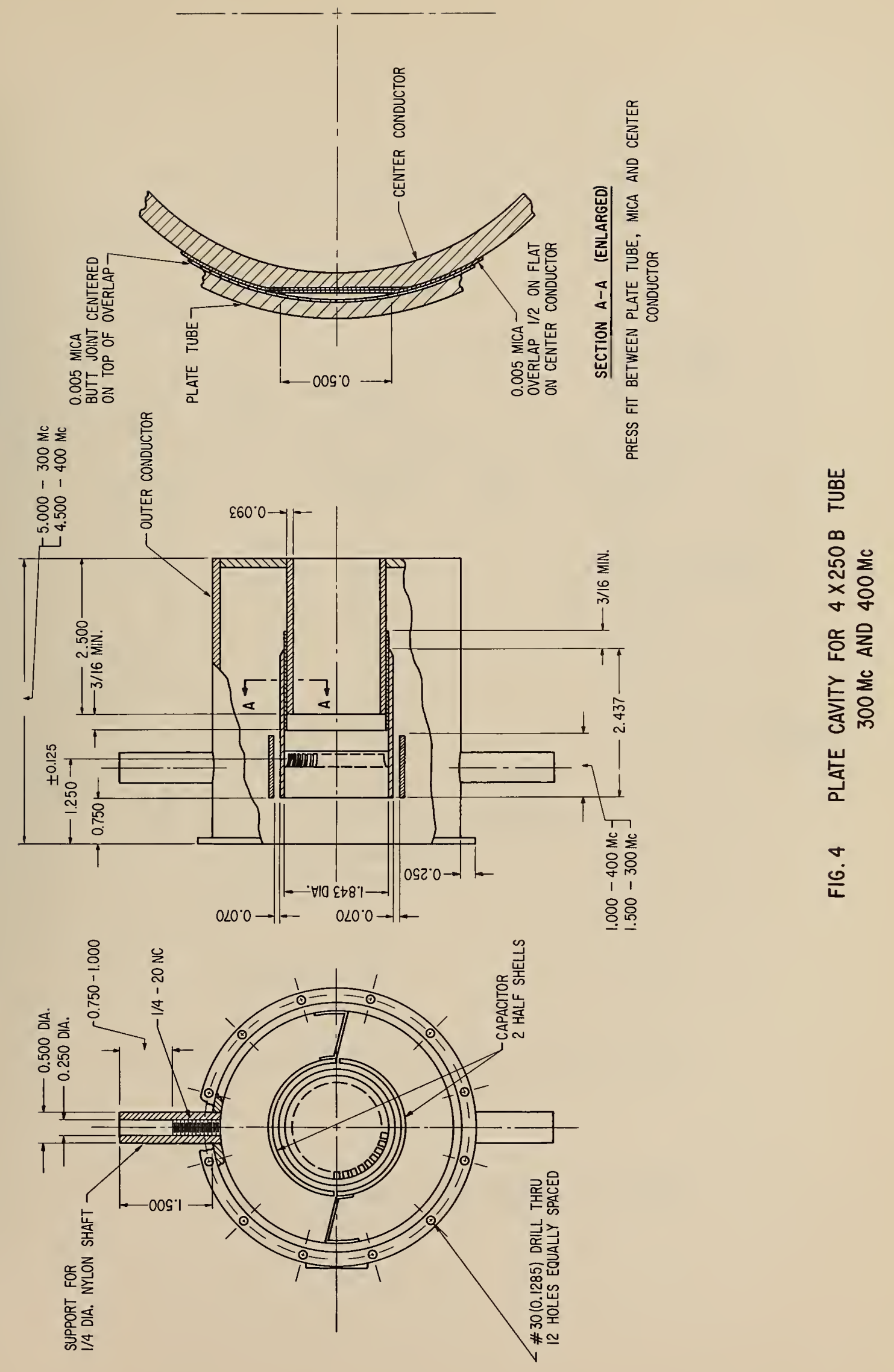




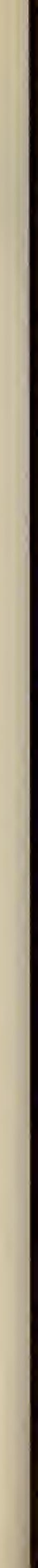




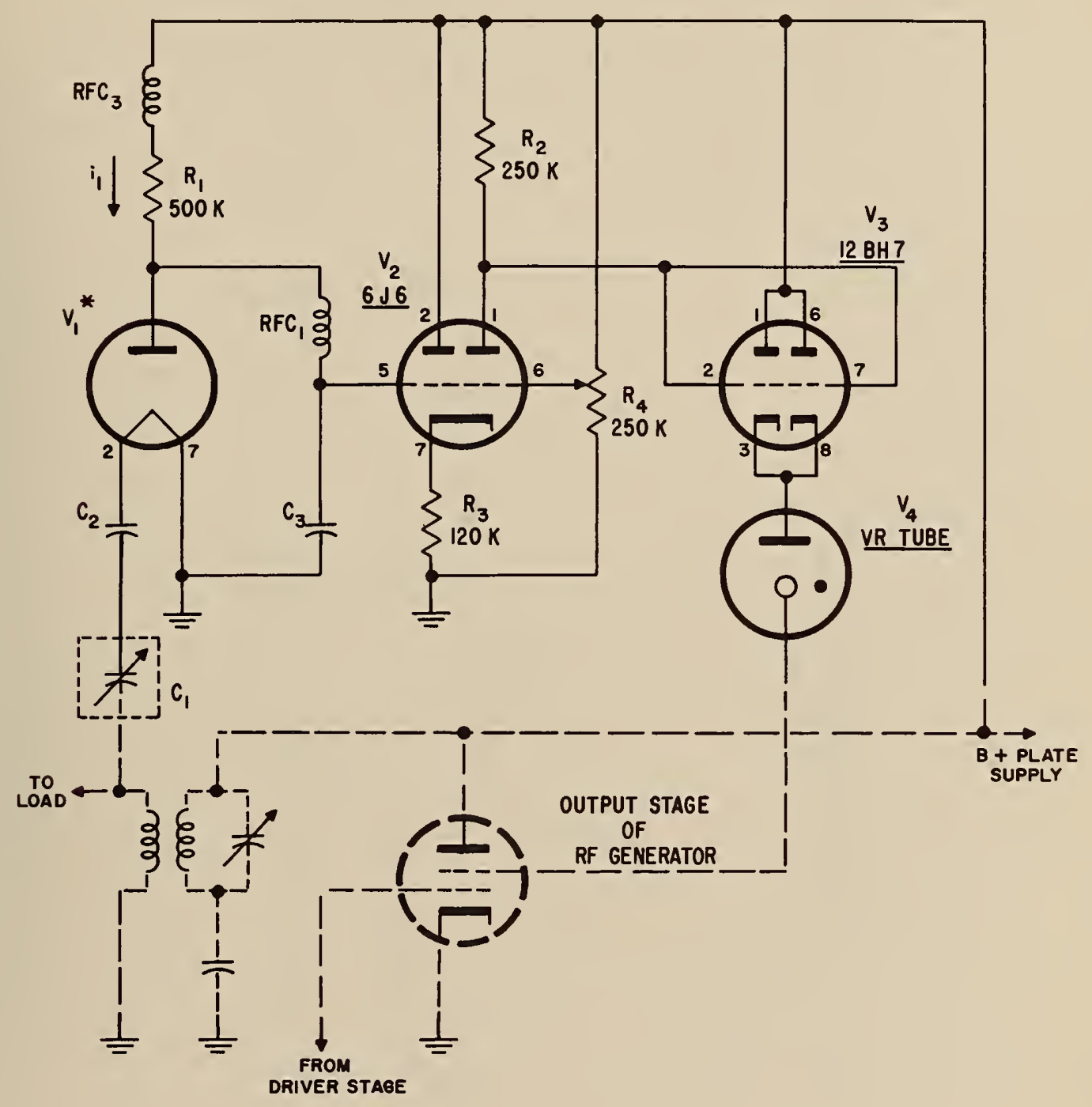

* kalotron type 2 as is or 2 Smi5 or superior elec. co. TyPe $1236 \mathrm{C}$

FIG. 5 AUTOMATIC LEVEL CONTROL (ALC) CIRCUIT 


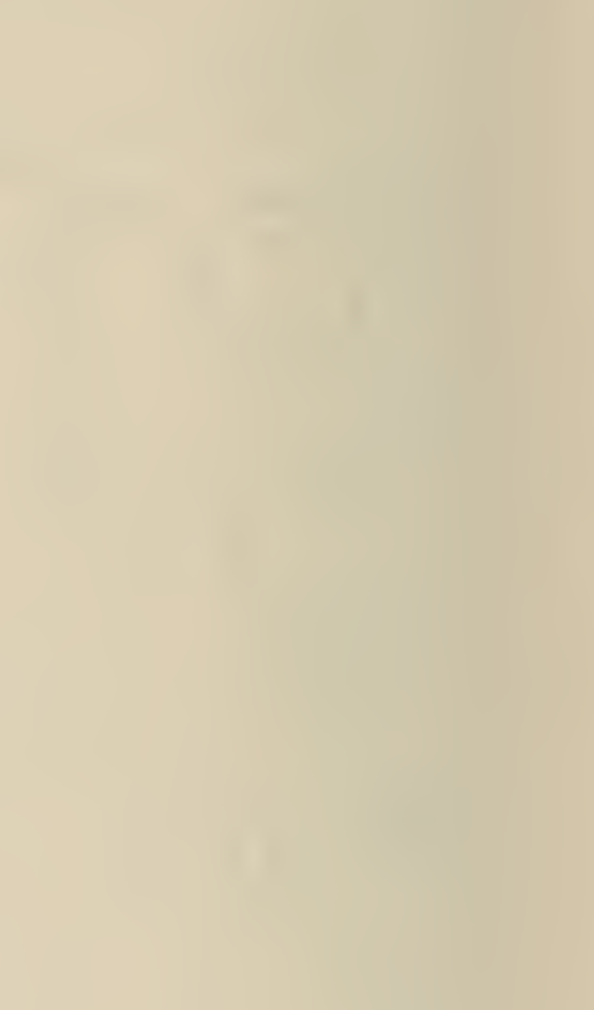



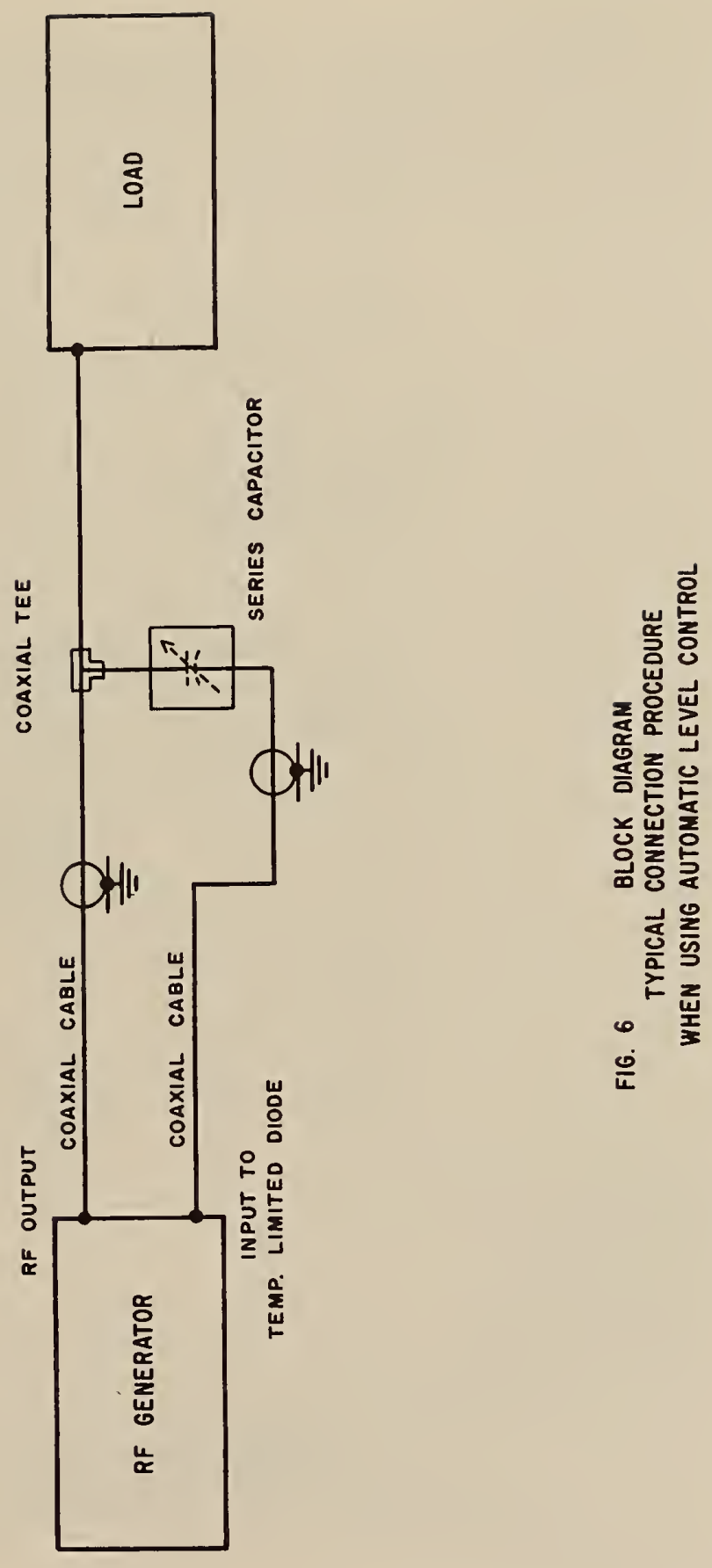


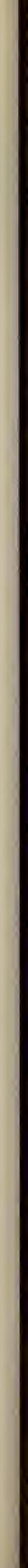




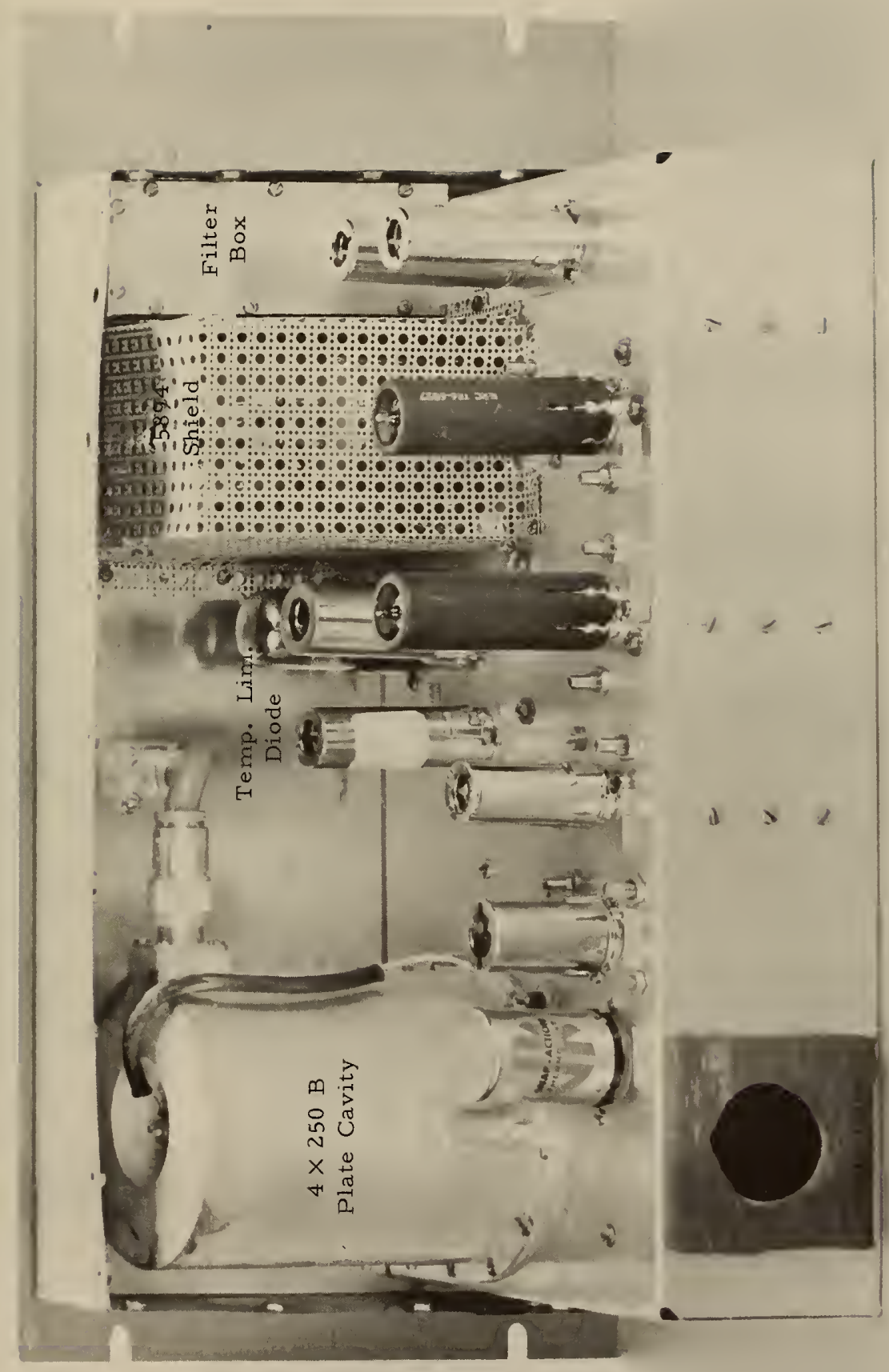

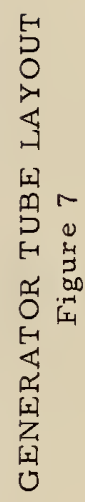




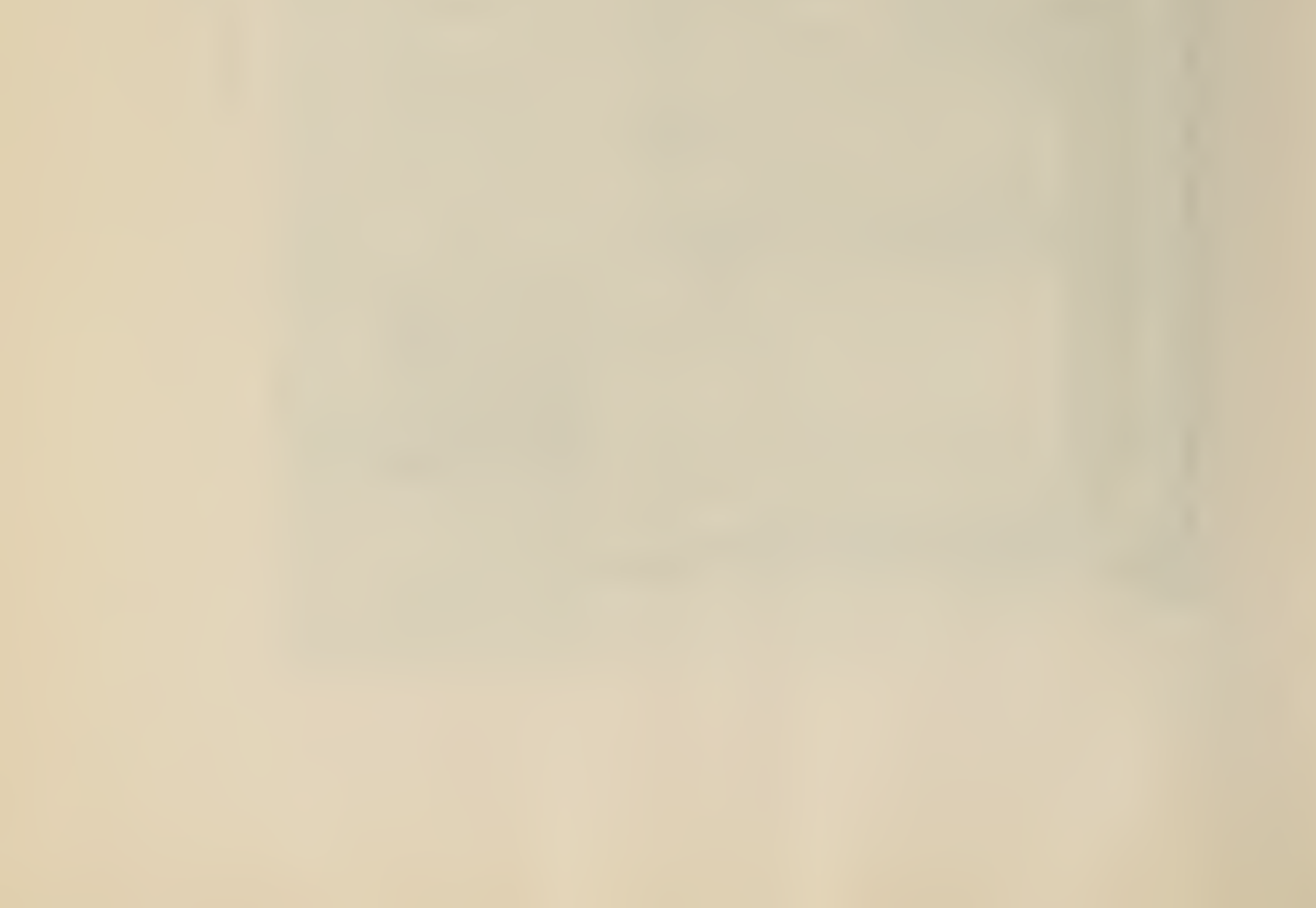



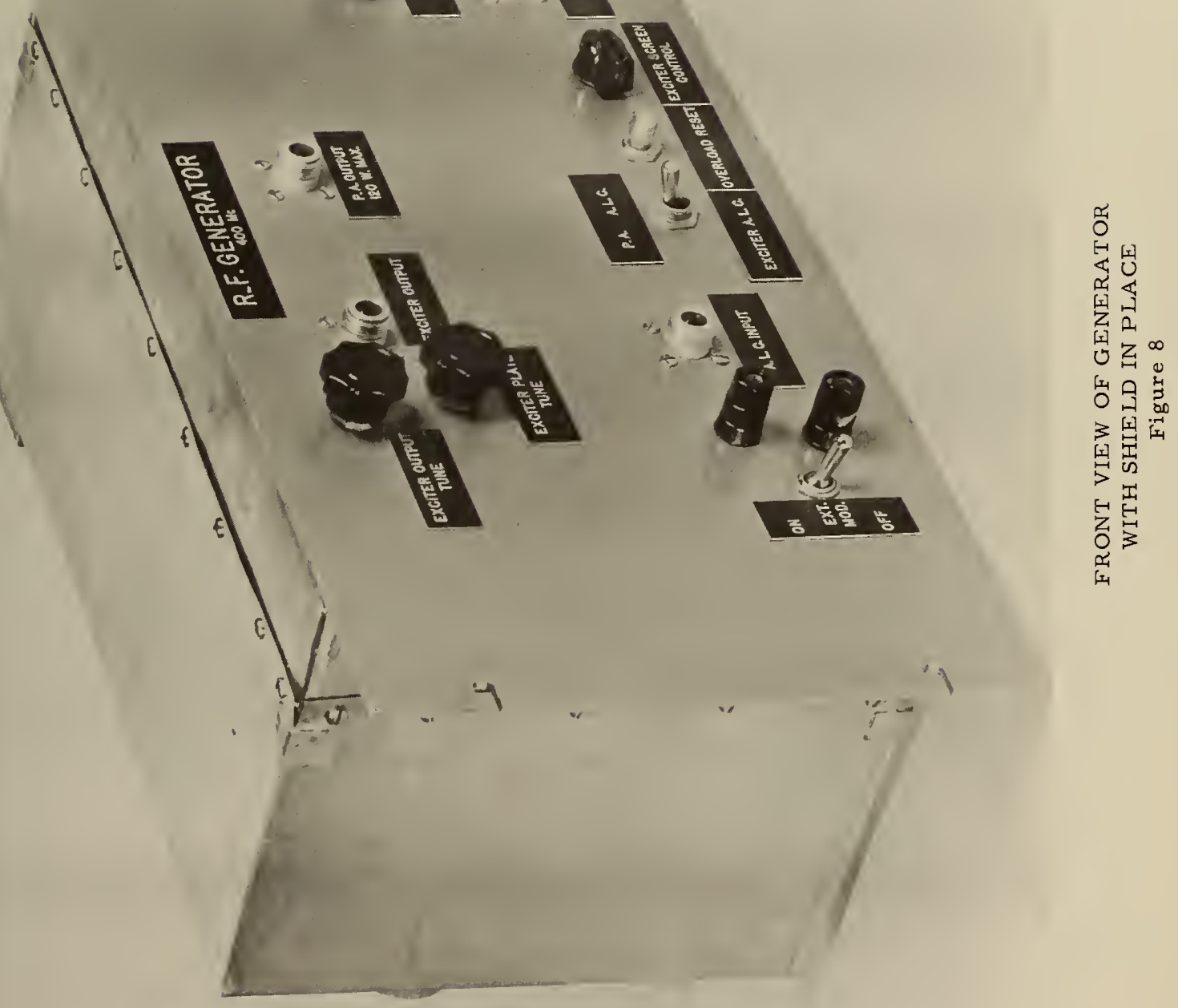

U.S. DEPARTMENT OF COMMERCE

Frederick H. Mueller, Secretary

NATIONAL BUREAU OF STANDARDS

A. V. Astin, Director

\section{THE NATIONAL BUREAU OF STANDARDS}

The scope of activities of the National Bureau of Standards at its major laboratories in Washington, D.C., and Boulder, Colo., is suggested in the following listing of the divisions and sections engaged in technical work. In general, each section carries out specialized research, development, and engineering in the field indicated by its titlc. A brief description of the activities, and of the resultant publications, appears on the inside of the front cover.

II ASHINGTON, D.C.

ELECTRICITY. Resistance and Reactance. Electrochemistry. Electrical Instruments. Magnetic Measurements. Dielectrics.

METROLOGY. Photometry and Colorimetry. Refractometry. Plotographic Research. Length. Engineering Metrology. Mass and Scale. Volumetry and Densimetry.

HEAT. Temperature Physics. Heat Measurements. Cryogenic Physics. Rheology. Molecular Kinetics. Free Radicals Research. Equation of State. Statistical Physics. Molecular Spectroscopy.

RADIATION PHYSICS. X-Ray. Radioactivity. Radiation Theory. High Energy Radiation. Radiological Equipment. Nucleonic Instrumentation. Neution Physics.

CHEMISTRY. Surface Chemistry. Organic Chemistry. Analytical Chemistry. Inorganic Chemistry. Electroit positioin. Molecular Structure and Properties of Gases. Physical Chemistry. Thermochemistr:y. Spectrochemistry. Pure Substances.

MECHANICS. Sound. Pressure and Vacuum. Fluid Mechanics. Engineering Mechanics. Combustion Controls. ORGANIC AND FIBROUS MATERIALS. Rubber. Textiles. Paper. Leather. Testing and Specifications. Polymer Structure. Plastics. Dental Research.

METALLURGY. Thermal Metallurgy. Cliemical Metallurgy. Mechanical Metallurgy. Corrosion. Metal Physics. MINERAL PRODUCTS. Engineering Ceramics. Glass. Refractories. Enameled Metals. Constitution and Microstructure.

BLILDING RESEARCH. Structural Engineering. Fire Research. Mechanical Systems. Or:ganic Building Materials. Codes and Safety Standards. Heat Transfer. Inorganic Building Materials.

APPLIED MATHEMATICS. Numerical Analysis. Computation. Statistical Engineering. Mathematical Physics.

DATA PROCESSING SYSTEMS. Components and Techniques. Digital Circuitry. Digital Systems. Analog Systens. Applications Engineering.

ATOMIC PHYSICS. Spectroscopy. Radiometry. Mass Spectrometry. Solid State Physics. Electron Physics. Atomic Physics.

INSTRUMENTATION. Engineering Electronics. Electron Devices. Electronic Instrumentation. Mechanical Instruments. Basic Instrumentation.

Office of Weights and Measures.

BOULDER, COLO.

CRYOGENIC ENGINEERING. Cryogenic Equipment. Cryogenic Processes. Properties of Materials. Gas Liquefaction.

IONOSPHERE RESEARCH AND PROPAGATION. Low Frequency and Very Low Frequency Research. Ionosphere Research. Prediction Services. Sun-Earth Relationships. Field Engineering. Radio Warning Services. RADIO PROPAGATION ENGINEERING. Data Reduction Instrumentation. Radio Noise. Tropospheric Measurements. Tropospheric Analysis. Propagation-Terrain Effects. Radio-Meteorology. Lower Atmosphere Physics. RADIO STANDARDS. High frequency Electrical Stanclards. Radio Broadcast Service. Radio and Microwave Materials. Atomic Frequency and Time Standards. Electronic Calibration Center. Millimeter-Wave Research. Microwave Circuit Standards.

RADIO SYSTEMS. High Frequency and Very High Frequency Research. Modulation Research. Antenna Resear:ch. Navigation Systems. Space Telecomınunications.

UPPER ATMOSPHERE AND SPACE PHYSICS. Upper Atmosphere and Plasma Physics. Ionosphere and Exosphere Scatter: Airglow and Aurora. Ionospheric Radio Astronomy. 


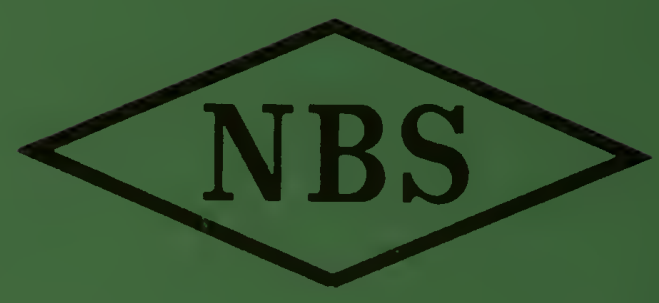

